\title{
QUANTIFYING PEST CONTROL SERVICES BY BIRDS AND ANTS IN KENYAN COFFEE FARMS
}

\author{
Megan C. Milligan ${ }^{1}$, Matthew D. Johnson ${ }^{1}$, Megan Garfinkel ${ }^{1}$, Chris J. Smith ${ }^{1}$ and Peter \\ Njoroge $^{2}$
}

${ }^{1}$ Humboldt State University, Department of Wildlife, 1 Harpst Street, Arcata, CA 95521

${ }^{2}$ National Museums of Kenya, Ornithology Section, P.O. Box 78420-00500 Ngara Road, Nairobi, Kenya

Corresponding author: Megan Milligan, 5035 Acacia Road, Las Cruces, NM 88011, megan.milligan11@gmail.com, +1 575 571-3518

\begin{abstract}
Ecosystem services, such as pest control and pollination, are critical benefits of biodiversity important for agricultural production. Predators, including insectivorous birds and ants, can provide important biological controls in agroecosystems, boosting crop yield and offsetting the need for expensive inputs such as pesticides. Local habitat and landscape characteristics can affect the delivery of ecosystem services, thereby influencing optimal land allocation for crop production and biodiversity. In order to better understand the relationship between ecosystem services and the surrounding habitat, we conducted a sentinel pest experiment to investigate predation levels in response to a novel pest on coffee farms in central Kenya. The frequency of predation decreased significantly with increasing distance from adjacent forest fragments and was correlated with bird species richness. Predation was also significantly higher on shade compared to sun coffee farms. We conclude that a land sharing approach, via both the integration of shade trees and the conservation of small forest fragments within or adjacent to a farm, can support increased levels of pest control services provided by birds and ants in Kenyan coffee farms.
\end{abstract}

Keywords: biodiversity, coffee, ecosystem services, Kenya, pest control, sentinel pest

\section{Introduction}

Global crop demand is projected to increase by 70 percent between 2005 and 2050 (FAO 2009). Meeting the rising agricultural demand will require some combination of increased land conversion and intensified production, which both pose serious threats to biodiversity. Two divergent strategies to optimize commodity production and biodiversity conservation in the face of land scarcity have emerged: the land sparing and land sharing strategies (Fischer et al. 2014). With land sparing, agricultural areas are managed intensively, creating the maximum agricultural yield from a minimal area, so that other areas can be "spared for nature" (Green et al. 2005). Land sharing, however, encourages biodiversity within each farm (Fischer et al. 2008), whether 
by including areas that are structurally similar to native vegetation or having high levels of heterogeneity within the farmed area or along the margins. Realistically, the optimal strategy will involve both approaches, and research that moves beyond this simple dichotomy is urgently needed (Kremen 2015). For example, encouraging wildlife that provide ecosystem services, such as pest control, could actually elevate yield (Şekercioğlu 2006), so that reductions in acreage, either from incorporating heterogeneity within the farm or preserving other land for nature, may not result in a net loss to the farmer.

Understanding the effects of different agricultural management strategies on biodiversity can help farmers better promote beneficial ecosystem services such as pest control. Coffee farms can significantly influence biodiversity on a large scale, because coffee is the most valuable tropical export crop in the world, cultivated on 10 million hectares worldwide (FAO 2012) with a value of approximately US $\$ 90$ billion (Jaramillo et al. 2011). Coffee has received attention in the land sparing versus land sharing debate due to the range of available management practices at the scale of both individual farms and landscapes, which enables comparison of current management practices (Chandler et al. 2013). Shade coffee, or coffee grown under a tree canopy, is a widely promoted example of the land sharing strategy because it can support significant onfarm biodiversity (Perfecto and Vandermeer 2015). In contrast, sun coffee monocultures, which possess lower vegetation complexity, typically have lower on-farm biodiversity but higher crop yields. If this higher production can offset yield lost on land protected for biodiversity, then sun coffee paired with preserved forest fragments may constitute a viable land sparing strategy. Despite a strong pattern suggesting that shade coffee supports greater biodiversity than sun monocultures (Armbrecht and Perfecto 2003; Raman 2006; Kellermann et al. 2008; Philpott et al. 2008; Philpott and Bichier 2012), there is no clear consensus regarding the effects of land sharing versus land sparing management strategies on biodiversity in coffee, in part because few studies have examined the differences explicitly (but see Phalan et al. 2011 and Chandler et al. 2013). In addition, surrounding habitats can play a role in determining on-farm biodiversity, with adjacent forest being found in some cases to exert a stronger influence on bird populations than farm attributes such as shade trees (Bátary et al. 2011).

Encouraging optimal land allocation for biodiversity can, in turn, benefit agriculture. The "insurance hypothesis" (McNaughton 1977; Tscharntke et al. 2005) holds that biodiversity stabilizes an ecosystem and buffers environmental disruptions, such as the expansion and irruption of agricultural pests in response to climate change. Due to climate change, coffee pests, such as berry borer (Hypothenemus hampei), are projected to shift in both range and abundance (Jaramillo et al. 2011) with responses of individual species being highly context-dependent (Jonsson et al. 2014). One limiting factor in agriculture, particularly in the developing world, is the availability of expensive inputs, such as pesticides (Ndang'ang'a et al. 2013a). By encouraging the provisioning of ecosystem services, including pest control, farmers could decrease their reliance on costly chemical inputs (Şekercioğlu 2012). Therefore, it is vital to gain a better understanding of the provisioning of natural pest control services.

Both bird and arthropod populations play a role in the provisioning of natural pest control services. Strong evidence suggests that bird population characteristics, such as diversity and composition, affect the provisioning of these services. Studies have shown that bird species richness (Perfecto et al. 2004; Van Bael et al. 2008), bird density (Perfecto et al. 2004), functional richness (Philpott et al. 2009), both species richness and predator abundance (Jedlicka et al. 2011), and the presence of migratory species (Van Bael et al. 2008) are all positively correlated with the top-down control of pests. However, despite this suite of work in the 
Neotropics, very few studies have examined pest control services provided by birds in Africa (De Beenhouwer et al. 2013). In addition to birds, arthropod predators, particularly ants, have been shown to be pest control agents in a variety of agroecosystems (Perfecto and Castiñeiras 1998; Philpott and Armbrecht 2006), including coffee (Vandermeer et al. 2002; Armbrecht and Perfecto 2003).

While the relationships between biodiversity and agricultural intensification, as well as between predator communities and pest control services, are well documented in coffee (Vandermeer et al. 2002; Armbrecht and Perfecto 2003; Perfecto et al. 2004; Van Bael et al. 2008; Philpott et al. 2009), few studies have examined the effect of farm and landscape variables on natural pest predation (Maas et al. 2015). Many studies have been conducted on Neotropical coffee farms, but very little work has been conducted in Africa (De Beenhouwer et al. 2013), where pest regulation may differ substantially because coffee is a native crop. While few studies have examined pest populations in coffee, shade coffee farms in Ethiopia were found to harbor a diverse community of insectivorous birds (Buechley et al. 2015) and predators and pollinators together decreased herbivory and increased fruit set in Tanzania (Classen et al. 2014). Taken together, these studies suggest that predator communities could be providing important pest control services on East African coffee farms. In addition, natural pest control has been observed in another African crop, kale, where pest reductions have been positively linked to both shade (Guenat 2014) and the influence of avian predators, although only during the dry season (Ndang'ang'a 2013b). Given that Africa accounts for roughly $20 \%$ of land devoted to global coffee production (FAO 2012), the region merits further study.

We investigated pest removal by conducting a sentinel pest experiment on coffee farms in central Kenya. We compared the frequency of pest removal to landscape characteristics, farm vegetation complexity, and both bird and ant community parameters to examine how different land management strategies affected the provisioning of pest control services.

\section{Methods}

\subsection{Study system}

We conducted this experiment in Nyeri County of central Kenya, located in the agriculturally productive highlands. Coffee farms range from large estates to small-scale plots embedded in a larger non-coffee habitat matrix, and cultivation practices include both sun and shade coffee, or coffee grown under a canopy of trees. In this study area, farms were either sun coffee ( $0 \%$ canopy cover) or shade monoculture as classified by Moguel and Toledo (1999). Shade coffee is uncommon in this region, and shade farms that existed had less canopy cover (mean $=20 \%$ ) and vegetative diversity (average of 1.4 shade tree species per site) than has been described for shade farms in the Neotropics (Moguel and Toledo 1999). Overall, we monitored 21 sites for pest predation, including 11 in sun coffee and 10 in shade coffee. A site consisted of two transects of pest presentation stations (see Sentinel Pest Experiment) and all sites were a minimum of $250 \mathrm{~m}$ apart to preserve independence. The sole exception was a pair of sites that were a minimum of $75 \mathrm{~m}$ apart, but were judged to be independent based on low bird recapture rates between the sites (<1\% recapture rate between sites, Smith 2015). Sites were located on five farms: Dedan Kimathi University of Technology (DKUT) Farm (120 ha), Jungle Estate (51 ha), Hill Estate (334 ha), Kihuri Estate (19 ha), and Sasini Farms (210 ha). All sites within a single farm were located within different coffee blocks, which were discrete areas with distinct management conditions and histories. 


\subsection{Sentinel pest experiment}

We performed a sentinel pest experiment to simulate elevated levels of a novel insect pest. This experiment controlled the location and quantity of pests, thus allowing the response rate to be measured in relation to hypothesized predictor variables, such as distance to forest fragment and the presence of shade trees. All sentinel pest experiments were performed in the dry season during a four week period in December 2012 and January 2013 and a six week period in December 2013 and January 2014.

For the experiment we chose large insects that were easy to manipulate and posed no threat to cooperating farmers. The maize stemborer caterpillar (Sesamia calamistis) is a common crop pest in Africa and is commercially available from the International Centre of Insect Physiology and Ecology (ICIPE), from which we obtained third instar larvae. While lepidopteran larvae are relatively rare on coffee plants (our arthropod sampling revealed an average of 0.03 larvae per branch), they are an important food item for birds (Greenberg 1995) and thus provide useful subjects for short-term assays of overall insect removal. While this approach cannot reveal true pest removal rates, it can provide a measure of predation in relation to forest fragments and farm vegetation complexity (sensu Perfecto et al. 2004).

A pest presentation station consisted of caterpillars on three adjacent coffee plants. Each coffee plant had two caterpillars placed on a single leaf at a height of $1.5 \mathrm{~m}$ and in the same cardinal direction. We pinned caterpillars to the leaf with a black enamel insect pin (Bioquip \#3) inserted through the caterpillar's thorax and secured below the leaf with green painter's tape. We placed caterpillars by dawn each morning to eliminate predation by nocturnal predators, and checked and collected them by 12:15. The discovery during the 2013-2014 field season that ants (predominantly Pheidole megacephala) were a source of predation prompted a modification to the setup of the pest presentation stations. During the second half of the 2013-2014 field season, we protected half of the branches with an ant barrier containing a mixture of Mortein Insect Spray (active ingredients: Allethrin [2.09 g/kg] and Resmethrin [0.39 g/kg]) and petroleum jelly (Vaseline) to prevent access by ants in order to estimate minimum bird and ant predation. Field trials proved that the ant barrier effectively excluded ants for a minimum of 12 hours.

Due to the low prevalence of shade coffee in the study region, no shade farms directly adjacent to forest fragments were available. Therefore, we only examined the effect of forest edge on sun coffee farms. Sites were $250 \mathrm{~m}$ apart and every sun coffee site contained two transects a minimum of $100 \mathrm{~m}$ apart. Each transect consisted of pest presentation stations placed at $0 \mathrm{~m}, 10 \mathrm{~m}, 25 \mathrm{~m}, 50 \mathrm{~m}, 75 \mathrm{~m}, 100 \mathrm{~m}, 125 \mathrm{~m}$, and $150 \mathrm{~m}$ from the forest fragment edge (Figure 1). This design allowed us to analyze the effect of distance to forest edge on pest removal on sun farms using stations from $0-100 \mathrm{~m}$. We excluded stations at $125 \mathrm{~m}$ and $150 \mathrm{~m}$ on the transect from the distance analysis because they were often less than $100 \mathrm{~m}$ from the opposite farm edge. Shade coffee sites had $100 \mathrm{~m}$ long transects, also a minimum of $100 \mathrm{~m}$ apart, with six pest presentation stations positioned along the transect, all at least $25 \mathrm{~m}$ from the coffee edge. Preliminary analyses suggested that the edge effect from forest fragments decreased significantly by $25 \mathrm{~m}$ (see Results for full analyses). Therefore, for comparisons of pest removal on sun and shade coffee sites, we excluded presentation stations at $0 \mathrm{~m}$ and $10 \mathrm{~m}$ from sun coffee sites and distance was not included as a variable, yielding six stations per transect in both sun and shade sites, all a minimum of $25 \mathrm{~m}$ from the nearest forest edge. By excluding presentation stations closer to the edge, the potential edge effect should also be removed, thus allowing the comparison of vegetation structure between sun and shade coffee farms. 
We set up motion sensor cameras (Reconyx HC500 HyperFire Semi-Covert IR) at a sample of the presentation stations in an attempt to determine which species were feeding on the caterpillars. On average, eight cameras were placed at each site for a total of 122 camera-stations in the study. Cameras were placed a minimum of 1-2 $\mathrm{m}$ away from the presentation station to minimize any effects on predator visitation.

\subsection{Landcover variables}

Adjacent forest fragments differed in size and quality, but were all composed of secondary growth with a mixture of native and non-native trees. To examine whether the size of conterminous forest affected pest removal, we digitized the adjacent forest fragments in GoogleEarth by identifying contiguous areas dominated by trees. We estimated the area of each resulting fragment in ArcMAP 10.1. To capture differences in the larger non-coffee matrix surrounding each site, we calculated the proportion of each landcover type within a $125 \mathrm{~m}$ buffer around each site. We digitized landcover layers in GoogleEarth based on the color and texture of the satellite image and on-the-ground knowledge of the habitat. The resulting layers were divided into the following landcover types: trees, brush, sun coffee, shade coffee, human structures, water, and other. We calculated the percentage of each landcover type within a $125 \mathrm{~m}$ buffer in Program R (Version 3.0.1) using the rgeos package.

\subsection{Vegetation variables}

To test the prediction that shade coffee supports higher levels of pest control, we analyzed the influence of the farm's vegetation complexity on predation. At each pest presentation station, we sampled coffee and shade tree vegetation in a $5 \mathrm{~m}$ radius plot. For coffee, measurements included coffee density (the proportion of the sample plot covered by coffee bushes), number of coffee bushes, percent understory (height $<1.5 \mathrm{~m}$ ) cover, percent midstory (height 1.5-5 m) cover, and the average height of both the mid- and understory. We calculated the volume of the understory vegetation by visually estimating the height and percent cover of vegetation in the sample plot. We calculated the volume of the midstory vegetation in the same manner but included only vegetation between $1.5-5 \mathrm{~m}$ tall, thus excluding any understory vegetation. Measurements of shade trees included percent shade cover (measured with a densiometer), the number of trees within $50 \mathrm{~m}$ of each plot, an estimate of shade tree density using the point-quarter method (Krebs 1989), and the distance to nearest tree in each quadrant (measured using a rangefinder), including its species, canopy depth (the distance from the bottom to the top of the tree canopy), and trunk height (the distance from the ground to the bottom of the canopy). We also calculated shade tree diversity for each transect using the Shannon-Wiener diversity index based on the proportion of trees of each species occurring within $25 \mathrm{~m}$. To preserve their utility for management purposes, vegetation variables were analyzed independently and not combined and summarized.

\subsection{Predator variables}

Both birds and ants were important predators in this system. We obtained information on bird species richness, abundance and composition from concurrent research of the bird populations at each site (Smith et al. 2015). Two transects of mist nets followed the spatial sampling design of the sentinel pest experiment. Mist nets were operated after, but within 28 days of, the sentinel pest experiment to avoid altering bird behavior during the experiment (see Smith 2015 for details on mist net operation). While mist nets are biased against birds that forage in the canopy, they sample the understory and are considered an effective method for sampling the bird community in coffee (Chandler et al. 2008, Buechley et al. 2015, Smith et al. 2015), which would capture any individuals potentially providing pest control services. Bird capture 
rates (per 100 net hours) provided an index of bird abundance. We calculated species richness as an average of the number of species captured at each distance for the distance analysis and for each transect for the full analysis (See Model Development and Selection below), because the capture rate was too low to allow for sufficient precision to estimate species richness at a net level. We classified species into five foraging guilds based on established groupings (Kissling et al. 2007). Birds were also classified based on their level of forest dependence (Bennun et al. 1996), with forest birds considered to be either forest specialists or forest generalists. Predictor variables used in the analysis included total abundance, species richness, insectivore abundance, and forest bird abundance. Our study was conducted in accordance with Humboldt State University's Institutional Animal Care and Use Committee (IACUC; Protocol \#13/14.W.39-A).

An index of ant abundance at each distance was calculated using tuna fish baits (Philpott et al. 2006). A strip of canned tuna (shredded, packed in oil) $4-5 \mathrm{~cm}$ wide was placed on each coffee trunk approximately $1 \mathrm{~m}$ above the ground. Baits were examined 30 minutes after they were placed, the number of ants present was counted and, when necessary, samples were collected for identification by the National Museums of Kenya to estimate species richness. 2.6 Arthropod variables

We conducted a survey of overall arthropod abundance on the coffee plants to determine background levels of larval abundance in order to place the sentinel pest experiment in context. Following the protocol described by Johnson (2000), we surveyed the arthropod community at each pest presentation station by taking 2-3 branch samples. We identified arthropods to order in the field and recorded the number and length of individuals in each order.

\subsection{Model development and selection}

This experiment included two similar analyses that addressed separate but related questions examining the underlying mechanisms driving total pest removal. The first analysis focused primarily on the effect of distance from forest edge on pest removal, while the second analysis concentrated on the effect of farm type (sun vs. shade coffee) on pest removal. Because only sun coffee farms were directly adjacent to forest fragments in this study system, the first analysis (distance) was performed only on this subset of the data. Ant variables were only measured during the 2013-2014 field season. Thus, the full analysis included only bird variables when examining the influence of the predator community, but a similar analysis was performed on a subset of the data to include both bird and ant variables.

To determine the relative importance of the different variables as predictors of pest removal, we used generalized linear mixed models with a binomial distribution in the lme 4 package in Program R. The proportion of caterpillars removed at a pest presentation station was the response variable with site and transect as nested random effects. Due to the large number of predictor variables under consideration, we used hierarchical model selection to build a set of candidate models for each analysis that were compared using the corrected Akaike's Information Criterion (AICc). The null model included both random effects, but no fixed effects. Vegetation variables were the first fixed effects considered as they presumably have a foundational influence on the other factors analyzed. To build a top vegetation model, we examined the AICc of each model with a single variable and included in subsequent analyses only variables that decreased the AICc over the null model. Once we chose a top model including only vegetation variables, we then considered variables, depending on the analysis, in the following order: landcover variables or farm type, predator variables, and distance. We averaged final models to yield coefficient estimates and we then assessed model fit by computing both marginal and conditional $\mathrm{R}^{2}$ values following the method outlined by Nakagawa and Schielzeth (2013). 


\section{Results}

Predation ranged between zero and $100 \%$ at individual pest presentation stations, with a mean of $11.8 \%$ of the caterpillars removed. Only birds and ants were identified eating the caterpillars in the sentinel pest experiment using motion-activated camera footage. Birds removed an average of at least $3.9 \%$ of the caterpillars and ants removed an average of at least $1.9 \%$ of the caterpillars, while the remaining $6 \%$ could not be conclusively assigned to birds or ants. A total of 85 bird species were captured and, of those species, 36 were classified as insectivores.

\subsection{Effects of distance to forest fragment on pest removal}

A mean of $12.0 \%$ of the pest presentation stations used in the distance analysis were depredated. Among the vegetation variables, the best predictors of pest removal included canopy cover, volume of midstory vegetation, tree density, and trunk height. When examined in combination with the top vegetation model, none of the landcover variables improved the AICc, but each landcover model had a small portion of the model weight. Therefore, we examined each landcover variable individually compared to the null model. As none improved the AICc fit over the null model, we did not include landcover variables in any further analysis. When bird population parameters were analyzed with the vegetation variables, the best model included forest bird abundance, with $62 \%$ of the model weight spread between a model including both the vegetation variables and forest bird abundance and a model including the vegetation variables and total bird abundance. In the final set of candidate models, the variable of distance was in all six top models, representing $100 \%$ of the model weight (Table 1). In the single strongest model $(\triangle \mathrm{AICc}=0$, model weight $=0.58)$ distance (Figure 2$)$, bird species richness, volume of midstory vegetation, tree density, and trunk height were negatively correlated with removal, while canopy cover was positively correlated. The second strongest model included distance, total bird abundance and vegetation variables, but represented only $15 \%$ of the model weight. The marginal and conditional $\mathrm{R}^{2}$ for the top model were 0.02 and 0.33 , respectively, indicating that while the model fit the data reasonably well, there remained substantial variation in predation rates unexplained by the variables in the top model.

\subsection{Effects of farm type on pest removal}

Among the vegetation variables, the best predictors of pest removal included canopy cover (Figure 3), which was positively correlated with removal, and coffee density and shade tree diversity, which were negatively correlated with removal. These three vegetation variables in combination were better predictors of pest removal than the simple binary variable of farm type and so were included in all further models. When combined with the bird population parameters, the model with the strongest support (Table $2 ; \Delta \mathrm{AICc}=0$, model weight $=0.35$ ) included the vegetation variables and insectivore abundance, which was negatively correlated with removal. However, model weight was spread fairly evenly over the top model and the following two models, which included just the vegetation variables $(\triangle \mathrm{AICc}=0.76$, model weight $=0.24)$, and vegetation and species richness, which was positively correlated with removal $(\triangle \mathrm{AICc}=0.83$, model weight $=0.23)$, respectively. The marginal $\mathrm{R}^{2}$ and conditional $\mathrm{R}^{2}$ for the top model were 0.03 and 0.39 , respectively, suggesting that again much variation remained unexplained by the top model.

Ants were present at $92 \%$ of the pest presentation stations and abundance at the tuna baits ranged from 0 to greater than 1000 individuals $($ mean $=207)$. Four ant genera were identified, but Pheidole megacephala was overwhelming the most numerous, accounting for 
over $90 \%$ of total abundance. Using only data from the 2013-2014 field season when ant variables were measured, ant abundance was in all eight of the top models, in combination with the different bird population variables, accounting for $80 \%$ of model weight, while ant species richness was not an important predictor of removal.

\section{Discussion}

Pest removal on Kenyan coffee farms was influenced by both how a farm was managed and its surroundings. In this experiment, pest removal was positively associated with shade tree canopy and, on sun farms, negatively associated with distance to an adjacent forest fragment. While our analyses showed clearly that canopy cover and distance to forest were important factors predicting pest removal, they also indicate that substantial variation in pest removal rates remains unexplained by the vegetation, landcover, and predator variables examined here. Therefore, a more complete understanding of the dynamics of pest removal rates in Kenyan coffee awaits further experimentation.

Percent canopy cover, the defining characteristic of shade coffee, was positively correlated with pest removal in all the models examining total predation, a finding consistent with some studies (e.g., Perfecto et al. 2004; Philpott and Armbrecht 2006; Armbrecht and Gallego 2007). However, this finding differs from other studies that found either no relationship between avian pest control and any measures of vegetation complexity, including canopy cover (Kellermann et al. 2008; Philpott et al. 2009), or a negative correlation (Johnson et al. 2010). The presence of shade trees could prompt a numerical response in both birds and ants foraging in coffee (Kellermann et al. 2008; Van Bael et al. 2008; Philpott et al. 2009), reflecting the tendency of predators to aggregate in areas of high prey density (Godfray and Pacala 1992). Alternatively, higher pest removal with increasing shade cover may be due to a functional response, whereby birds are more likely to detect and consume large profitable prey like caterpillars when they can search for them from above. Our results may differ from previous studies because Kenyan shade farms generally had low shade tree diversity and abundance, potentially increasing the incentive for predators to forage in the coffee layer compared to more diverse Neotropical shade farms. A simulation model based on data from Jamaican coffee farms found that if shade trees became too common, it was no longer profitable for birds to forage in the crop layer, where there are fewer prey (Railsback and Johnson 2014).

Pest removal on sun farms was also positively correlated with proximity to an adjacent forest fragment. Birds may nest or roost in forest patches and venture into the farm edge to forage (Jirinec et al. 2011). This finding underscores that adjacent habitat can contribute to the delivery of an ecosystem service by mobile organisms (Ricketts 2004; Kellermann et al. 2008; Wenny et al. 2011; Karp et al. 2013), and provide an incentive for habitat protection near farm edges. However, other landscape variables, including fragment size and the amount of forested area within a $125 \mathrm{~m}$ radius, were not associated with pest control. In addition, the number of forest birds was not related with pest removal. In this system, small patches of forest on sun farm edges appear to be sufficient to deliver insectivorous birds and ants into the farm, perhaps because predators in our system were not strongly forest dependent. This contrasts with a previous study suggesting that greater surrounding forest cover increased avian control of coffee berry borer on farms in Costa Rica (Karp et al. 2013).

Taken together, these results suggest that a land sharing approach, incorporating both shade trees within the farm and small forest patches on farm edges, could promote increased pest control services. Land sharing encourages biodiversity within the farm, and shade coffee, a 
widely promoted example, has been positively linked to pest control in the Neotropics (Philpott and Armbrecht 2006; Armbrecht and Gallego 2007). Our results extend this pattern to East Africa. Our finding that pest removal was not related to size of adjacent forest fragment, and the low removal rate more than $25 \mathrm{~m}$ from a forest edge (Figure 2), suggests that forest fragments only influence the provisioning of pest control services on a small spatial scale. Thus, a coarsely scaled land sparing system, coupling large blocks of sun coffee with preserved forest elsewhere, may not facilitate pest removal services provided by birds and ants in this study system. Instead, small patches of forest dispersed across the agricultural landscape would be more beneficial. In addition, the influence on pest control services of other forms of land sharing, such as the incorporation of hedges, riparian corridors, or single large trees, all of which were observed in our study area, should be examined in the future as they are often more practical on the smallholder farms still responsible for the majority of coffee production (Jha et al. 2014). Labeling land sparing and land sharing land allocations is scale-dependent (Fischer et al. 2014), and some may consider this scenario a finely scaled example of land sparing, but since it would be most realistically achieved by incentivizing individual land owners to conserve forest patches, it is more consistent with the practice of land sharing from a farmer's perspective.

While pest removal was positively correlated with canopy cover, other vegetation variables, including coffee density and shade tree diversity, had a negative influence on removal. Additional vegetation variables were important in the distance analysis, but due to the small sample size of sun coffee sites, we only drew conclusions about the importance of vegetation variables from the broader farm type analysis. Lower coffee densities could increase avian foraging success by making prey more conspicuous, resulting in the negative relationship we observed. In contrast to coffee densities, greater shade tree diversity would be expected to positively affect bird and ant diversity and thus pest control services, as has been shown on coffee farms in Mexico (Perfecto et al. 2004). However, the majority of shade coffee farms in this study system had very low levels of tree diversity, so these results should be interpreted with caution. Sites with a greater range of shade tree diversity should be included in future studies to determine if this result extends to other regions.

The frequency of pest removal in this study was a result of a combination of avian and ant predation, but results suggest that, of known removals, birds were responsible for up to twice as much predation as ants. Biodiversity has been linked to ecosystem stability and resilience (McNaughton 1977; Tscharntke et al. 2005), and, as this will become increasingly important with the expansion of pests as a result of climate change (Chapin et al. 2000), it is important to understand the effect of the predator community on the provisioning of pest control services. In the full analysis, bird abundance and species richness were positively correlated with pest removal, coinciding with results of previous studies that found positive relationships between bird abundance (Perfecto et al. 2004) and bird diversity (Perfecto et al. 2004; Van Bael et al. 2008) with the top-down control of pests.

However, while avian species richness had a positive effect on pest removal in the broader farm type analysis, it actually had a negative effect on removal in the distance analysis, which included only sun coffee sites. Species richness at the sun coffee sites was most likely driven by granivorous species, which were frequently observed foraging on the understory vegetation (M.C.M, personal observation), whereas the majority of insectivores were either forest generalist or forest visitor species (Bennun et al. 1996; Smith 2015). In addition, the abundance of insectivores was a poor predictor and was actually negatively related to pest removal. Functional richness has been suggested to be a more accurate predictor of ecosystem 
services (Philpott et al. 2009), and previous studies found insectivore abundance (Van Bael et al. 2008), functional richness (Philpott et al. 2009) and predator abundance (Jedlicka et al. 2011) to be positively correlated with the control of pests. While higher insectivore abundance would be expected to increase pest removal, 36 out of the 85 bird species detected in our study system were classified as primarily insectivorous (Smith et al. 2015) and it is possibly too broad a classification to be meaningful. Instead, a single abundant species or set of species could be driving pest removal as seen in a similar study in Indonesia (Maas et al. 2015). Some of these results are not what may be expected and, given that our sample size is modest, should be interpreted with some caution and await future confirmation.

Ant abundance was also positively correlated with pest removal, while ant species richness was not an important predictor of removal, a finding consistent with a study of pest removal by ants on a Mexican coffee plantation (De la Mora et al. 2008). This contrasts with a previous study that suggested that ant diversity could increase predator responses of ants (Philpott and Armbrecht 2006). In our system, however, ant species richness at the level of an individual coffee bush was very low, which could explain the lack of importance. Local ant abundance may be driven by farm vegetation characteristics such as canopy cover (Philpott 2005) or the spatial distribution of their nests, which Vandermeer and colleagues have found to be a factor affecting pest control by Azteca ants, a keystone species that nests in shade trees in Neotropical coffee agroecosystems (Vandermeer et al. 2008, 2010). Pheidole megacephala was overwhelmingly the most abundant carnivorous ant in our system. It is well-known to feed on honeydew excreted by scale insects, which it protects on plants by aggressively removing other insects, including lepidopteran larvae (Bach 1991), and this pattern has been confirmed in a coffee ecosystem (Reimer et al. 1993). Unlike Azteca ants, however, Pheidole megacephala nests underground, so it may not be as affected by shade tree cover or distribution. Working in Tanzania, Seguni et al. (2011) found that Pheidole megacephala suppressed numbers of arboreal predatory ants known to protect tree crops (Oecophylla sp.), but only if ground vegetation cover was low. Additional research should examine the influence of shade tree distribution and ground cover on the abundance and pest control services by ground- and tree-nesting ants in African coffee.

Other influences, including weather, mammalian predation, or human or mechanical error could be responsible for removals in sentinel pest experiments. These explanations are unlikely in our study because the result would likely be a random pattern, not the predictable influence of shade and distance to forest fragment apparent here. Caterpillars were placed just before dawn every morning to exclude nocturnal predators, mammals were rarely observed in the coffee during the day, and remote cameras only detected birds and ants visiting the caterpillars. In addition, all experiments were conducted in areas where the coffee was not being actively picked to avoid any influence of coffee workers. Consequently, the patterns observed in this experiment are most likely a result of some combination of avian and ant predation. However, our study was conducted during the dry season, and the time of year could influence bird and ant activity and thus their role as provisioners of pest control services. A previous study on Kenyan kale farms found a positive influence of birds on pests only during the dry season (Ndang'ang'a 2013b). Pest availability and intake presumably vary by season and the applicability of the patterns observed here to other seasons should be examined in the future.

In summary, both birds and ants are providing ecosystem services in coffee farms in central Kenya. The sentinel pest experiment mimicked a dramatic increase in a novel insect pest (from 0.03 to 2 lepidopteran larvae per branch) and a combination of birds and ants were able to 
460 remove $12 \%$ of pests over a period of about 6 hours. In addition, the different farm types and

461 surrounding habitat had a clear impact on pest control services. With coffee pests such as coffee

462 berry borer projected to expand in both range and abundance with climate change (Jaramillo et

463 al. 2011) and the impacts of different management strategies on pest populations being highly

464 context-dependent (Jonsson et al. 2014), the provisioning of natural pest control services will

465 only increase in importance. These results suggest that a land sharing approach, via both the

466 integration of shade trees and the conservation of small forest fragments within a farm, can

467 support increased levels of pest control services provided by both birds and ants in Kenyan

468 coffee farms.

469

470

\section{Acknowledgements}

471 We would like to thank the National Science Foundation for their financial support (NSF IRES

472 Grant \#1131725) and the National Museums of Kenya, particularly P. Gichuki, and Dedan

473 Kimathi University of Technology for their logistical support. None of this would have been

474 possible without the help and cooperation of all the farmers: J. Waumbibo from Jungle Estate, J.

475 Gathirwa from DKUT Farm, Mr. Njomo from Kihuri Estate, J. Mungai from Hill Estate, and J.

476 Thiga and Joseph from Sasini Farms. We would like to thank two anonymous reviewers for their

477 helpful comments. 
496

\section{References}

Armbrecht, I., Perfecto, I. 2003. Litter-twig dwelling ant species richness and predation potential within a forest fragment and neighboring coffee plantations of contrasting habitat quality in Mexico. Agriculture, Ecosystems and Environment 97:107-115.

Armbrecht, I., Gallego, M. 2007. Testing ant predation on the coffee berry borer in shaded and sun coffee plantations in Colombia. Entomologia experimentalis et Applicata 124:261-267.

Bach, C. 1991. Direct and indirect interactions between ants (Pheidole megacephala), scales (Coccus viridis) and plants (Pluchea indica). Oecologia 87:233-239.

Bátary, P., Báldi, A., Kleijn, D., Tscharntke, T. 2011. Landscape-moderated biodiversity effects of agri-environmental management: a meta-analysis. Proceedings of the Royal Society B:

Biological Sciences 278:1894-1902.

Bennun, L., Dranzoa, C., Pomeroy, D. 1996. The forest birds of Kenya and Uganda. Journal of East African Natural History 85:23-48.

Buechley, E., Şekercioğlu, Ç., Atickem, A., Gebremichael, G., Ndungu, J., Mahamued, B., Beyene, T., Mekonnen, T., Lens, L. 2015. Importance of Ethiopian shade coffee farms for forest bird conservation. Biological Conservation 188:50-60.

Chandler, R., King, D., Raudales, R., Trubey, R., Chandler, C., Chavez, V. 2013. A small-scale land-sparing approach to conserving biological diversity in tropical agricultural landscapes. Conservation Biology 27:785-795.

Chapin III, S., Zavaleta, E., Eviner, V., Naylor, R., Vitousek, P., Reynolds, H., Hooper, D., Lavorel, S., Sala, O., Hobbie, S., Mack, M., Diaz, S. 2000. Consequences of changing biodiversity. Nature 405:234-242.

Classen, A., Peters, M., Ferger, S., Helbig-Bonitz, M., Schmack, J., Maassen, G., Schleuning, M., Kalko, E., Böhning-Gaese, K., Steffan-Dewenter, I. 2014. Complementary ecosystem services provided by pest predators and pollinators increase quantity and quality of coffee yields. Proceedings of the Royal Society B: Biological Sciences 281 DOI: 10.1098/rspb.2013.3148.

De Beenhouwer, M., Aerts, R., Honnay, O. 2013. A global meta-analysis of the biodiversity and ecosystem service benefits of coffee and cacao agroforestry. Agriculture, Ecosystems and Environment 175:1-7.

De la Mora, A., Livingston, G., Philpott, S. 2008. Arboreal ant abundance and leaf miner damage in coffee agroecosystems in Mexico. Biotropica 40:742-746.

Fischer, J., Brosi, B., Daily, G., Ehrlich, P., Goldman, R., Goldstein, J., Lindenmayer, D., Manning, A., Mooney, H., Pejchar, L., Ranganathan, J., Tallis, H. 2008. Should agricultural 
policies encourage land sparing or wildlife-friendly farming? Frontiers in Ecology and the Environment 6:380-385.

Fischer, J., Abson, D., Butsic, V., Chappell, M., Ekroos, J., Hanspach, J., Kuemmerle, T., Smith, H., von Wehrden, H. 2014. Land sparing versus land sharing: moving forward, Conservation Letters 7:149-157.

Food and Agriculture Organization of the United Nations (FAO). 2009. State of Food Insecurity in the World 2009. FAO, Rome, Italy.

Food and Agriculture Organization of the United Nations (FAO). 2012. FAOSTAT Online Statistical Service, Rome, Italy. Available from http://faostat.fao.org (accessed November 2014).

Godfray, H., Pacala, S. 1992. Aggregation and the population dynamics of parasitoids and predators. The American Naturalist 140:30-40.

Green, R., Cornell, S., Scharlemann, J., Balmford, A. 2005. Farming and the fate of wild nature. Science 307:550-555.

Greenberg, R. 1995. Insectivorous migratory birds in tropical ecosystems: the breeding currency hypothesis. Journal of Avian Biology 260-264.

Guenat, S. 2014. Assessing the effects of agroforestry practices on biological control potential in kale (Brassica oleracea acephala) plantations in Western Kenya. Thesis, Swedish University of Agricultural Sciences, Uppsala, Sweden.

Jaramillo, J., Muchuga, E., Vega, F., Davis, A., Borgemeister, C., Chabi-Olaye, A. 2011. Some like it hot: the influence and implications of climate change on coffee berry borer (Hypothenemus hampei) and coffee production in East Africa. PLoS ONE (e24528) DOI: 10.1371/journal.pone.0024528.

Jedlicka, J., Greenberg, R., Letourneau, D. 2011. Avian conservation practices strengthen ecosystem services in California vineyards. PLoS ONE (e27347) DOI: 10.1371/journal.pone.0027347.

Jha, S., Bacon, C., Philpott, S., Méndez, E., Läderach, P., Rice, R. 2014. Shade coffee: update on a disappearing refuge for biodiversity. Bioscience 64:416-428.

Jirinec, V., Campos, B., Johnson, M. 2011. Roosting behaviour of a migratory songbird on Jamaican coffee farms: landscape composition may affect delivery of an ecosystem service. Bird Conservation International 21:353-361.

Johnson, M. 2000. Evaluation of an arthropod sampling technique for measuring food availability for forest insectivorous birds. Journal of Field Ornithology 71:88-109. 
Johnson, M., Kellermann, J., Stercho, A. 2010. Pest reduction services by birds in shade and sun coffee in Jamaica. Animal Conservation 13:140-147.

Jonsson, M., Raphael, I., Ekbom, B., Kyamanywa, S., Karungi, J. 2014. Contrasting effects of shade level and altitude on two important coffee pests. Journal of Pest Sciences DOI: 10.1007/s10340-014-0615-1.

Karp, D., Mendenhall, C., Sandi, R., Chaumont, N., Ehrlich, P., Hadly, E., Daily, G. 2013. Forest bolsters bird abundance, pest control and coffee yield. Ecology Letters 16:1339-1347.

Kellermann, J., Johnson, M., Stercho, A., Hackett, S. 2008. Ecological and economic services provided by birds on Jamaican Blue Mountain coffee farms. Conservation Biology 22:11771185.

Kissling, W., Rahbek, C., Böhning-Gaese, K. 2007. Food plant diversity as broad-scale determinant of avian frugivore richness. Proceedings of the Royal Society B 274:799-808.

Krebs, C. 1989. Ecological Methodology. HarperCollins Publishers, New York.

Kremen, C. 2015. Reframing the land-sparing/land-sharing debate for biodiversity conservation. Annals of the New York Academy of Sciences DOI: 10.1111/nyas.12845

Maas, B., Tscharntke, T., Shahabuddin, S., Putra, D.D., Clough, Y. 2015. Avian species identity drives predation success in tropical cacao agroforestry. Journal of Applied Ecology 52:735-743.

McNaughton, S. 1977. Diversity and stability of ecological communities: a comment on the role of empiricism in ecology. American Naturalist 111:515-525.

Moguel, P., Toledo, V. 1999. Biodiversity conservation in traditional coffee systems of Mexico. Conservation Biology 13:11-21.

Nakagawa, S., Schielzeth, H. 2013. A general and simple method for obtaining $\mathrm{R}^{2}$ from generalized linear mixed-effects models. Methods in Ecology and Evolution 4:133-142.

Ndang'ang'a, P., Njoroge, J., Ngamau, K., Kariuki, W., Atkinson, P., Vickery, J. 2013a. Avian foraging behaviour in relation to provision of ecosystem services in a highland East African agroecosystem. Bird Study 60:156-168.

Ndang'ang'a, P., Njoroge, J., Vickery, J. 2013b. Quantifying the contribution of birds to the control of arthropod pests on kale, Brassica oleracea acephala, a key crop in East African highland farmland. International Journal of Pest Management DOI: 10.1080/09670874.2013.820005.

Perfecto, I., Castiñeiras, A. 1998. Deployment of the predaceous ants and their conservation in agroecosystems. Pages 269-289 in Barbosa P, editor. Conservation biological control. Academic Press, Baltimore. 
Perfecto, I., Vandermeer, J., Bautista, G., Nuñez, G., Greenberg, R., Bichier, P., Langridge, S. 2004. Greater predation in shaded coffee farms: the role of resident neotropical birds. Ecology 85:2677-2681.

Perfecto, I., Vandermeer, J. 2015. Coffee agroecology: a new approach to understanding agricultural biodiversity, ecosystem services and sustainable development. Routledge, New York.

Phalan, B., Onial, M., Balmford, A., Green, R. 2011. Reconciling food production and biodiversity conservation: land sharing and land sparing compared. Science 333:1289-1291.

Philpott, S. 2005. Changes in arboreal ant populations following pruning of coffee shade-trees in Chiapas, Mexico. Agroforestry Systems 64:219-224.

Philpott, S., and Armbrecht, I. 2006. Biodiversity in tropical agroforests and the ecological role of ants and ant diversity in predator function. Ecological Entomology 31:369-377.

Philpott, S., Perfecto, I., Vandermeer, J. 2006. Effects of management intensity and season on arboreal ant diversity and abundance in coffee agroecosystems. Biodiversity and Conservation 15:139-155.

Philpott, S., Arendt, W., Armbrecht, I., Bichier, P., Diestch, T., Gordon, C., Greenberg, R., Perfecto, I., Reynoso-Santos, R., Soto-Pinto, L., Tejeda-Cruz, C., Williams-Linera, G., Valenzuela, J., Zolotoff, J. 2008. Biodiversity loss in Latin American coffee landscapes: review of the evidence on ants, birds, and trees. Conservation Biology 22:1093-1105.

Philpott, S., Soong, O., Lowenstein, J., Pulido, A., Lopez, D., Flynn, D., DeClerck, F. 2009. Functional richness and ecosystem services: bird predation on arthropods in tropical agroecosystems. Ecological Applications 19:1858-1867.

Philpott, S., Bichier, P. 2012. Effects of shade tree removal on birds in coffee agroecosystems in Chiapas, Mexico. Agriculture, Ecosystems and Environment 149:171-180.

Railsback, S., Johnson, M. 2014. Effects of land use on bird populations and pest control services on coffee farms. Proceedings of the National Academy of Sciences 111:6109-6114.

Raman, T. 2006. Effects of habitat structure and adjacent habitats on birds in tropical rainforest fragments and shaded plantations in the Western Ghats, India. Biodiversity and Conservation 15:1577-1607.

Reimer, N. J., Cope, M. L., Yasuda, G. 1993. Interference of Pheidole megacephala (Hymenoptera: Formicidae) with biological control of Coccus viridis (Homoptera: Coccidae) in coffee. Environmental Entomology 22:483-488. 
Ricketts, T. 2004. Tropical forest fragments enhance pollinator activity in nearby coffee crops. Conservation Biology 18:1262-1271.

Seguni, Z., Way, M., Van Mele, P. 2011. The effect of ground vegetation management on competition between the ants Oecophylla longinoda and Pheidole megacephala and implications for conservation biological control. Crop Protection 30:713-717.

Şekercioğlu, Ç. 2006. Increasing awareness of avian ecological function. Trends in Ecology and Evolution 21:464-471.

Şekercioğlu, Ç. 2012. Bird functional diversity and ecosystem services in tropical forests, agroforests and agricultural areas. Journal of Ornithology 153:153-161.

Smith, C. 2015. Bird communities in sun and shade coffee in Kenya. Thesis, Humboldt State University, Arcata, California, USA.

Smith, C., Barton, D., Johnson, M.D., Wendt, C., Milligan, M.C., Njoroge, P., Gichuki, P. 2015. Bird communities in sun and shade coffee farms in Kenya. Global Ecology and Conservation 4:479-490.

Tscharntke, T., Klein, A., Kruess, A., Steffan-Dewenter, I., Thies, C. 2005. Landscape perspectives on agricultural intensification and biodiversity - ecosystem service management. Ecology Letters 8:857-874.

Van Bael, S., Philpott, S., Greenberg, R., Bichier, P., Barber, N., Mooney, K., Gruner, D. 2008. Birds as predators in tropical agroforestry systems. Ecology 89:928-934.

Vandermeer, J., Perfecto, I., Nuñez, G., Philpott, S., Ballinas, A. 2002. Ants (Azteca sp.) as potential biological control agents in shade coffee production in Chiapas, Mexico. Agroforestry Systems 56:271-276.

Vandermeer, J., Perfecto, I., Philpott, S. 2008. Clusters of ant colonies and robust criticality in a tropical agroecosystem. Nature 451:457-459.

Vandermeer, J., Perfecto, I., Philpott, S. 2010. Ecological complexity and pest control in organic coffee production: uncovering an autonomous ecosystem service. BioScience 60:527-537.

Wenny, D., DeVault, T., Johnson, M., Kelly, D., Şekercioğlu, Ç., Tomback, D., Whelan, C. 2011. The need to quantify ecosystem services provided by birds. The Auk 128:1-14. 
Table 1. Support for the final set of models predicting the probability of caterpillar depredation in the distance analysis.

\begin{tabular}{|l|c|c|c|c|c|c|}
\hline \multicolumn{1}{|c|}{ Model } & K & AICc & $\Delta$ AICc & $\boldsymbol{w}_{\boldsymbol{i}}$ & Cumulative $\boldsymbol{w}_{\boldsymbol{i}}$ & $\mathbf{L L}$ \\
\hline $\begin{array}{l}\text { Vegetation* + species richness + } \\
\text { distance }\end{array}$ & 9 & 262.87 & 0.00 & 0.58 & 0.58 & -121.62 \\
\hline $\begin{array}{l}\text { Vegetation + total abundance + } \\
\text { distance }\end{array}$ & 9 & 265.59 & 2.72 & 0.15 & 0.72 & -122.98 \\
\hline Vegetation + distance & 8 & 265.94 & 3.07 & 0.12 & 0.85 & -124.32 \\
\hline $\begin{array}{l}\text { Vegetation + forest bird } \\
\text { abundance + distance }\end{array}$ & 9 & 267.41 & 4.53 & 0.06 & 0.91 & -123.88 \\
\hline Distance & 4 & 268.01 & 5.14 & 0.04 & 0.95 & -129.83 \\
\hline $\begin{array}{l}\text { Vegetation + insectivore } \\
\text { abundance + distance }\end{array}$ & 9 & 268.04 & 5.17 & 0.04 & 1.00 & -124.20 \\
\hline $\begin{array}{l}\text { Vegetation + forest bird } \\
\text { abundance }\end{array}$ & 8 & 274.55 & 11.67 & 0.00 & 1.00 & -128.63 \\
\hline Vegetation + total abundance & 8 & 275.38 & 12.50 & 0.00 & 1.00 & -129.04 \\
\hline Vegetation & 7 & 275.55 & 12.67 & 0.00 & 1.00 & -130.27 \\
\hline Vegetation + species richness & 8 & 277.50 & 14.63 & 0.00 & 1.00 & -130.10 \\
\hline $\begin{array}{l}\text { Vegetation + insectivore } \\
\text { abundance }\end{array}$ & 8 & 277.81 & 14.94 & 0.00 & 1.00 & -130.26 \\
\hline Null & 393.98 & 31.11 & 0.00 & 1.00 & -143.89 \\
\hline Vegetation mon & & & & & \\
\hline
\end{tabular}
vegetation, tree density, and trunk height. 
704 Table 2. Support for the final set of models predicting the probability of caterpillar depredation 705 in the farm type analysis.

\begin{tabular}{|l|c|c|c|c|c|c|}
\hline \multicolumn{1}{|c|}{ Model } & K & AICc & $\Delta$ AICc & $\boldsymbol{w}_{\boldsymbol{i}}$ & Cumulative $\boldsymbol{w}_{\boldsymbol{i}}$ & $\mathbf{L L}$ \\
\hline $\begin{array}{l}\text { Vegetation* + insectivore } \\
\text { abundance }\end{array}$ & 7 & 508.82 & 0.00 & 0.35 & 0.35 & -247.16 \\
\hline Vegetation & 6 & 509.58 & 0.76 & 0.24 & 0.59 & -248.61 \\
\hline Vegetation + species richness & 7 & 509.65 & 0.83 & 0.23 & 0.82 & -247.58 \\
\hline Vegetation + total abundance & 7 & 511.58 & 2.76 & 0.09 & 0.91 & -248.55 \\
\hline $\begin{array}{l}\text { Vegetation + forest bird } \\
\text { abundance }\end{array}$ & 7 & 511.70 & 2.88 & 0.08 & 0.99 & -248.61 \\
\hline Null & 3 & 517.27 & 8.46 & 0.01 & 1.00 & -255.58 \\
\hline
\end{tabular}

*Vegetation model includes the following variables: canopy cover, coffee density, and shade tree 707 diversity. 
Figure 1. Experimental design of the sentinel pest experiment in sun coffee farms. Each letter (A, $\mathrm{B}, \mathrm{C})$ represents a single coffee plant with two caterpillars on the same leaf.

Figure 2. Model prediction of the probability of predation at increasing distance from an adjacent forest fragment. Dashed lines represent $95 \%$ confidence intervals. Points represent the actual proportion of caterpillars removed in the sentinel pest experiment and were jittered to make overlapping points distinctly visible.

Figure 3. Model prediction of the probability of predation with increasing canopy cover. Dashed lines represent $95 \%$ confidence intervals. Points represent the actual proportion of caterpillars 718 removed in the sentinel pest experiment. 
Figure 1

\section{Forest Edge}

$0 \mathrm{~m}$ A B C

$10 \mathrm{~m}$

$25 \mathrm{~m}$

A B C

$50 \mathrm{~m}$

\section{A B C}

A B C

A B C

$75 \mathrm{~m}$

A B C

A B C

$100 \mathrm{~m}$

$$
\text { A B C }
$$

A B C

$125 \mathrm{~m}$

A B C

A B C

$150 \mathrm{~m}$

$$
\text { A B C }
$$$$
\text { A B C }
$$ 
Figure 2

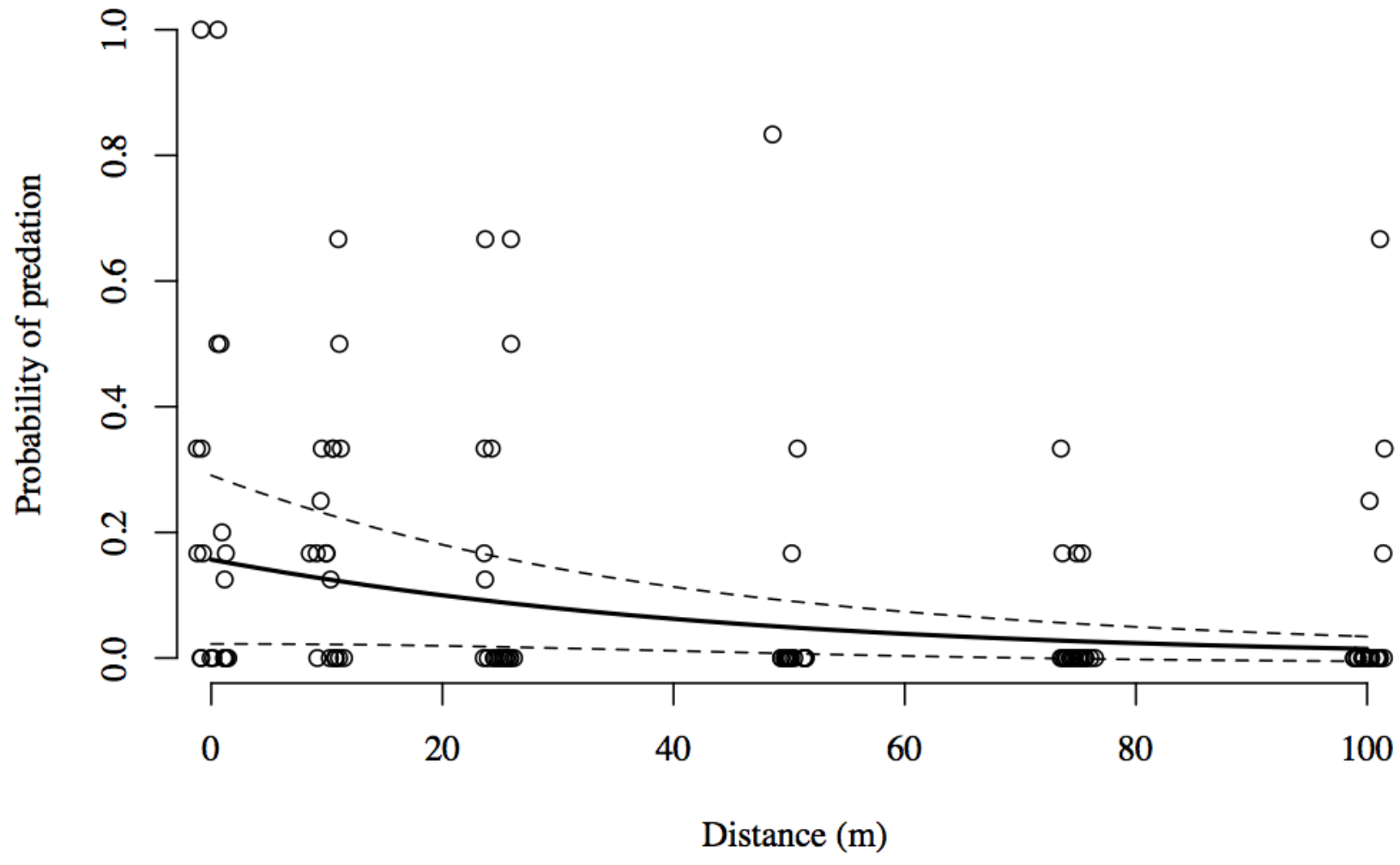


Figure 3

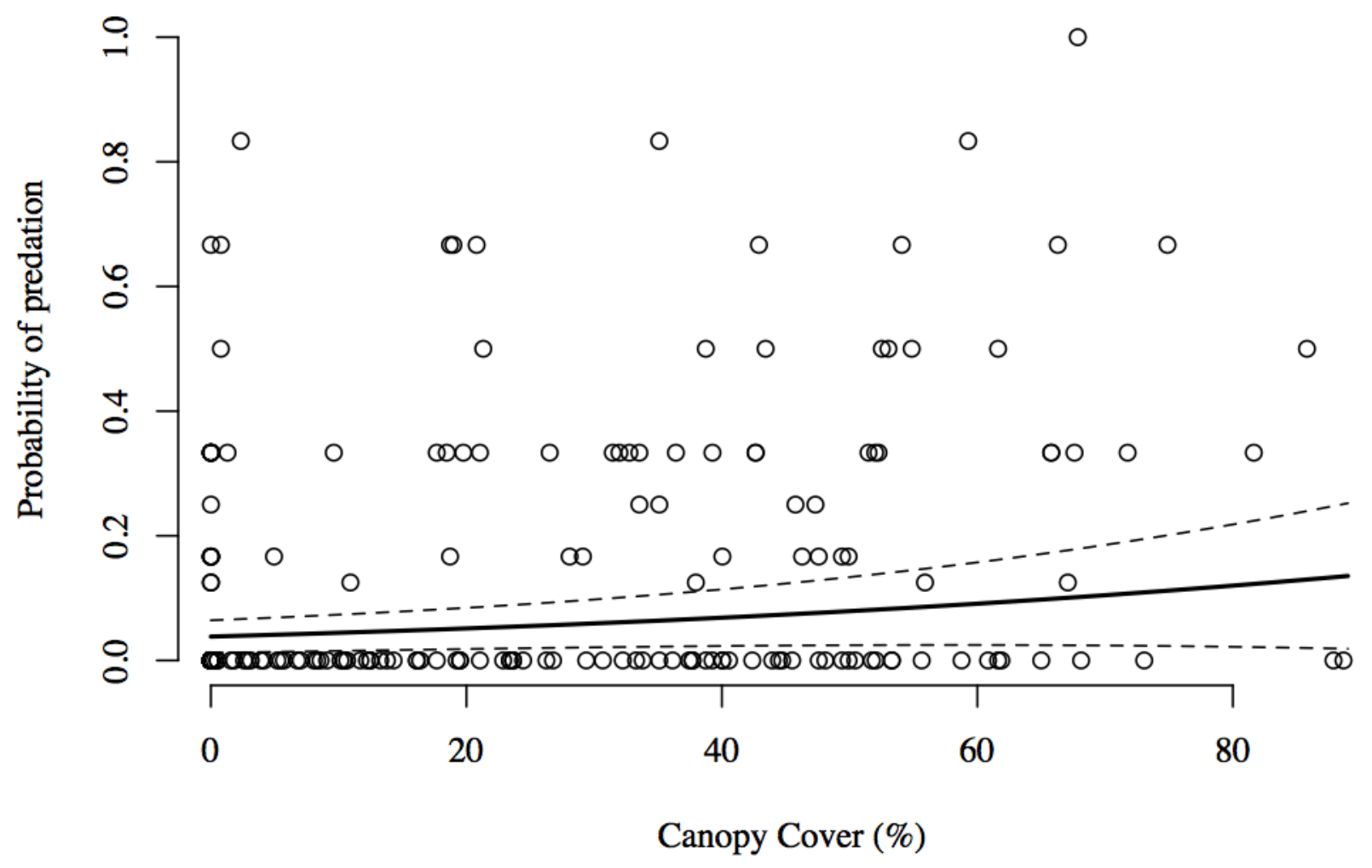

